\title{
El Hábeas Data en las provincias argentinas y en la Ciudad Autónoma de Buenos Aires
}

Oscar Raúl Puccinelli

\section{Marco conceptual}

Como ya lo explicamos en otra oportunidad ${ }^{1}$, el registro de antecedentes, referencias o datos ${ }^{2}$ relativos a las personas, si bien no es un fenómeno nuevo, no generó demasiados conflictos sino hasta el advenimiento de la denominada "era de las computadoras", la cual trajo consigo la "revolución informática" y otros cambios tan extraordinarios, que permiten -con escaso esfuerzo e inusitada facilidad- el almacenamiento, tratamiento y trasmisión de datos mediante bases ${ }^{3}$ y bancos de datos $^{4}$.

Esta posibilidad de generar a través de las nuevas tecnologías gran cantidad y calidad de información, sumada a los notables avances en

1 Ver "Hábeas Data: aportes para una eventual reglamentación", en E.D., 161-913.

2 El vocablo "dato" alude a un elemento circunscrito y aislado (v.gr., nombre o nacionalidad), que no alcanza a tener el carácter de información, pues para que se trasforme en ella se requiere la interconexión de esos datos de manera que, vinculados, se conviertan en una referencia concreta (v.gr., nombre y nacionalidad). Los actuales sistemas permiten, por ejemplo, entrelazar datos seleccionados y obtener las referencias solicitadas en pocos segundos, e incluso transferir lo deseado a la computadora de quien consulta.

3 Cuando los datos son agrupados de manera que forman una colección de información consistente en ensayos, números, diagramas y similares, organizada sistemáticamente de modo que pueda ser analizada por un computador electrónico, configuran una base de datos (cfr. ley japonesa 64/86, citada por Carlos Correa y otros: Derecho informático, Depalma, Bs. As., 1994, p. 302).

4 Cuando las bases de datos están organizadas en conjunto y son accesibles en línea (directamente de una computadora), sirviendo así para la consulta de datos de la más diversa índole, se trasforman en un banco de datos (cfr.: Correa y otros: op. cit. en nota 3, p. 299). 
materia de telecomunicaciones, constituyen los ingredientes principales de un cóctel tan útil para quienes acceden a la información almacenada, como peligroso para los registrados en ella, especialmente por cuanto, aún cuando se pueda considerar a los datos almacenados como "inocentes" o carentes de importancia, la suma o entrelazamiento de ellos desde una o más bases o bancos de datos permite que, en la práctica, se llegue a desnudar la intimidad de las personas, haciendo ilusorias las garantías constitucionales ${ }^{5}$.

La potencial explosividad de esta nueva situación —en especial cuando de información sensible se trata ${ }^{6}$-, sumada al hecho de que quien cuenta con buena información cuenta con una importante cuota de poder económico y político, ha llevado a la doctrina a hablar de un nuevo poder: el "poder informático"7.

Así las cosas, muchas veces ocurren agudos conflictos entre los derechos de los registradores - que pregonan en su favor la "libertad informática" ${ }^{-}$- y los de los registrados — que oponen a aquella su "derecho a la autodeterminación informativa" - en especial, con los

5 Esta posibilidad ha sido bien descrita por Luis $\mathrm{O}$. Andorno en "La informática y el derecho a la intimidad", L.L., t. 1985-A, p. 1108.

6 Esta es la información que atañe, generalmente, a cuestiones íntimas de las personas (religión, raza, conducta sexual, opinión política, etc.), y se encuentra bien descrita por Sagüés en "El Hábeas Data Impacto de la Informática en la sociedad", L.L. t. 1987-E., p. 859 citada por Néstor Pedro Sagüés en "El Hábeas Data: alcances y problemática" conferencia pronunciada en la Universidad de Lima el 23/11/93, cuya trascripción textual en el Diario de Sesiones de la Convención Nacional Constituyente fue solicitada por el convencional constituyente por Santa Fe, Iván José María Cullen, al ser debatido en particular el texto constitucional del Hábeas Data, el 16/8/94.

7 Éste permite, entre infinidad de supuestos, entorpecer o agilizar transacciones comerciales; facilitar la formación o el combate de monopolios u oligopolios; dar marco para prevenir o preparar delitos; hacer proyecciones electorales; conocer y proporcionar aspectos íntimos de las personas, tanto para hostilizarlas como para venderles productos (pensemos solamente en la infinita información que tienen los sistemas de tarjetas de crédito), etc.

8 Pérez Luño entiende que éste es un nuevo derecho fundamental, propio de la tercera generación (Hábeas Corpus, amparo, Hábeas Data y acción de cumplimiento: normatividad vigente, Comisión Andina de Juristas, Lima, 1994, p. 12).

9 Tal derecho garantiza la facultad de las personas para conocer y acceder a las informaciones que les conciernen, archivadas en bancos de datos; controlar su calidad - lo cual implica la posibilidad de corregir o cancelar los datos inexactos o indebidamente procesados-, y disponer sobre su trasmisión (Antonio E. Pérez Luño, "Los derechos humanos en la sociedad tecnológica", en Mario Losano y otros, Libertad informática y leyes de protección de datos personales, CEC, Madrid, 1989, p. 140, citado en Hábeas Corpus, amparo, Hábeas Data y acción de cumplimiento: normatividad vigente, Comisión Andina de Juristas, Lima, 1994, p. 12). 
derechos a la intimidad, al honor, a la propia imagen, a la identidad; e incluso con otros, como el derecho de propiedad, potencialmente amenazado si se diera a conocer datos legítimamente almacenados pero que deben permanecer en reserva (v.gr., la fórmula química de un producto, la composición patrimonial o los detalles relativos a los negocios de una empresa, etc.).

A los efectos de poner algunos límites a los problemas generados, se han creado algunos mecanismos especiales, entre los cuales se cuentan los procedimientos secretos de carácter judicial o administrativo (v.gr., Constitución del Brasil, Art. $5^{\circ}$, numeral LXVII) y el Hábeas Data ("presenten los datos"), que no es más que un amparo especializado, cuya misión consiste en brindar protección inmediata y efectiva a los derechos fundamentales afectados por las prácticas de almacenamiento, procesamiento y suministro de datos ${ }^{10}$, y que pueden estar consagrados a nivel constitucional o legal, según el ordenamiento de que se trate $^{11}$.

Desde las primeras constituciones que se ocuparon de la problemática de la protección de datos personales -España ${ }^{12}$ y Portuga $1^{13}$-, es conocido el proceso de recepción de estas normas en diversas constitu-

10 Cabe recordar que el concepto de protección de datos ha variado, pues en los primeros años de aplicación de las leyes de protección de datos la discusión se centraba en la antítesis "vida privada versus computadoras». En el actual estado tecnológico, la protección de datos es una sintesis de los intereses individuales y sociales en juego (cfr.: Paul Sieghart: Legislation and data protection. Proceedings on the Roma Conference of problems relating to the development and aplication of legislation on data protection. Council of Europa, Camera dei Deputati, Roma, 1983, p. 16, citado por Correa y otros, op. cit. en nota 3, p. 249).

11 Algunos autores sostienen que la incorporación constitucional es innecesaria, pues para proteger los derechos basta con regular adecuadamente el proceso de amparo; además, una inadecuada actuación judicial, así como una mala regulación procesal, podrían propiciar excesos que afecten la libertad de expresión (Hábeas Corpus..., op. cit. en nota 9, p. 13).

12 "Art. $18^{\circ} .-[\ldots]$ 4) La ley limitará el uso de la informática para garantizar el honor y la intimidad personal y familiar de los ciudadanos y el pleno ejercicio de sus derechos".

13 «Art. 35\%.- "1. Todos los ciudadanos tienen derecho a tomar conocimiento de los datos constantes en ficheros o registros informáticos a su respecto $y$ del fin a que se destinan, pudiendo exigir su rectificación y actualización, sin perjuicio de lo dispuesto en la ley sobre secreto de Estado y secreto de justicia.

2. Es prohibido el acceso a ficheros y registros informáticos para conocimiento de datos personales relativos a terceros y respectiva interconexión, salvo en casos excepcionales previstos en la ley.

3. La informática no puede ser utilizada para el tratamiento de datos referentes a convicciones filosóficas o políticas, filiación partidaria o sindical, fe religiosa o vida privada, salvo cuando se 
ciones latinoamericanas ${ }^{14}$, entre las cuales se ha colocado recientemente la Argentina, a nivel federal, y de las autonomías locales.

En lo que hace a este trabajo, centraremos la cuestión en los aspectos relativos a las regulaciones habidas en las provincias argentinas y en la Ciudad Autónoma de Buenos Aires, comparándolas con la norma establecida a nivel federal, para determinar sus respectivos alcances.

trate de procesamiento de datos estadísticos no individualmente indentificables.

4. La ley define el concepto de datos personales para efectos de registro informático, bien como de bases y bancos de datos y respectivas condiciones de acceso, constitución y urilización por entidades públicas y privadas.

5. Es prohibida la atribución de un número nacional único a los ciudadanos.

6. La ley define el régimen aplicable a los flujos de datos trasfronteras, estableciendo formas adecuadas de protección de datos personales y de otros cuya salvaguarda se justifique por razones de intereses nacionales."

(La versión original prescribía: «Todos los ciudadanos tendrán derecho a tomar conocimiento de lo que conste en forma de registros mecanográficos acerca de ellos y de la finalidad a que se destinan las informaciones, y podrán exigir la rectificación de datos, así como su actualización. No se podrá utilizar la informática para el tratamiento de datos referentes a convicciones políticas, fe religiosa o vida privada, salvo cuando se trate de la elaboración de datos no identificables para fines estadísticos. Se prohíbe atribuir un número nacional único a los ciudadanos").

14 Brasil: «Art. $5^{\circ}$.- [...] (LXXII) Se concede Hábeas Dara: a) para asegurar el conocimiento de informaciones relativas a la persona del solicitante contenidas en registros o bancos de datos, de entidades gubernamentales o de carácter público; b) para la rectificación de datos, cuando no se prefiera hacerlo por procedimiento secreto de carácter judicial o administrativon.

[...] (LXVII) «Serán gratuitas las acciones de Hábeas Corpus y Hábeas Data y, en la medida en que la ley lo disponga, los actos necesarios para el ejercicio de la ciudadanía.

Colombia: «Art. $15^{\circ}$.- Todas las personas tienen derecho a su intimidad personal y familiar y a su buen nombre, y el Estado debe respetarlos y hacerlos respetar. De igual modo, tienen derecho a conocer, acrualizar $y$ rectificar las informaciones que se hayan recogido sobre ellas en bancos de datos y en archivos de entidades públicas y privadas. En la recolección, tratamiento y circulación de los datos se respetarán la libertad y demás garantías consagradas en la Constitución".

Guatemala: «Art. $31^{\circ}$.- Toda persona tiene el derecho de conocer lo que de ella conste en archivos, fichas o cualquier otra forma de registros estatales, y la finalidad a que se dedica. Quedan prohibidos los registros y archivos de filiación política, excepto los propios de las autoridades electorales y de los partidos políticosn.

Paraguay: “Art. $135^{\circ}$.- Toda persona puede acceder a la información y a los datos que sobre sí misma, o sobre sus bienes, obren en registros oficiales o privados de carácter público, así como conocer el uso que se haga de los mismos y de su finalidad. Podrá solicitar ante el magistrado comperente la actualización, rectificación o la destrucción de aquéllos, si fuesen erróneos o afectaran ilegítimamente sus derechos".

Perú: «Art. $200^{\circ}$.- Son garantías constitucionales: [...] 3) La acción de Hábeas Data, que procede contra el hecho u omisión por parte de cualquier autoridad, funcionario o persona, que vulnera o amenaza los derechos a que se refiere el Art. $2^{\circ}$, incs. 5 y 6 , de la Constitución". 


\section{La protección de datos personales en la Argentina.}

Hasta la regulación realizada por el Art. $43^{\circ}$ de la Constitución Argentina -que se limita al Hábeas Data ${ }^{15}$ y aún no cuenta con ley reglamentaria ${ }^{16}$ - a nivel federal se debatieron varios proyectos normativos tendientes a regular el tratamiento de datos.

En el ámbito provincial, a partir del proceso constituyente pre y postrreformista que arrancó con el regreso a la democracia en 1983, varias constituciones se ocuparon -aunque con distintos alcances- de ciertos aspectos relativos a los datos personales, en particular regulando el Hábeas Data ${ }^{17}$.

Mientras algunas provincias consideraron en sus constituciones sólo un aspecto de la protección de datos personales, ocupándose de los antecedentes policiales y penales (La Rioja, Salta y San Juan), o de establecer el derecho de acceso a las fuentes de información (Catamarca y Formosa -además de Río Negro y San Luis, que por otra parte también regularon el Hábeas Data-), otras fueron más allá, consagrando al Hábeas Data como acción específica de garantía (Buenos Aires - Ciudad A utónoma y provincia—, Córdoba, Chaco, Chubut, La Rioja, Jujuy,

"Art. $2^{\circ}$. Toda persona tiene derecho [...] 5. A solicitar sin expresión de causa la información que requiera y a recibirla de cualquier entidad pública, en el plazo legal, con el costo que suponga su pedido. Se exceptúan las informaciones que afectan la intimidad personal y las que expresamente se excluyan por ley o por razones de seguridad nacional.[...] 6. A que los servicios informáricos, computarizados o no, públicos o privados, no suministren informaciones que afecten la intimidad personal o familiar.n. Cabe apuntar que a poco de entrar en vigencia la Carta de 1993, su primera reforma suprimió la remisión al Art. $2^{\circ}$, Inc. 7 de la Constitución, que regulaba la garantía (ordinariamente denominado "derecho") de réplica.

15 "Art. $\left.43^{\circ} .-1 ..\right]$ Toda persona podrá interponer esta acción (se refiere a la de amparo) para tomar conocimiento de los datos a ella referidos y de su finalidad, que consten en registros o bancos de datos públicos, o los privados destinados a proveer informes, $y$ en caso de falsedad o discriminación, para exigir la supresión, rectificación, confidencialidad o actualización de aquéllos. No podrá afectörse el secreto de las fuentes de información periodística".

16 El 27 de noviembre de 1996, el Congreso de la Nación sancionó el proyecto de ley $\mathrm{n}^{\circ} 24.745$, que incluía una primera parte donde regulaba aspectos relativos al tratamiento de datos personales en general y también el Hábeas Data, pero fue vetado en su totalidad por el Poder Ejecutivo el 23 de diciembre de 1996, que a su vez remitió a las Cámaras una iniciativa propia al respecto, y que aún no ha sido objeto de tratamiento legislativo.

17 Ciudad Autónoma de Buenos Aires: "Art. 16․- Toda persona tiene, mediante una acción de amparo, libre acceso a todo registro, archivo o banco de datos que conste en organismos públicos o en los privados destinados a proveet informes, a fin de conocer cualquier asiento sobre su persona, su fuente, origen, finalidad o uso que del mismo se haga. 
También puede requerir su actualización, rectificación, confidencialidad o supresión, cuando esa información lesione o restrinja algún derecho.

El ejercicio de este derecho no afecta el secreto de la fuente de información periodística."

Provincia de Buenos Aires: "Art. 20 .- Se establecen las siguientes garantías de los derechos constitucionales:[...] 3. A través de la garantía de Hábeas Data, que se regirá por el procedimiento que la ley determine, toda persona podrá conocer lo que conste de la misma en forma de registro, archivo o bancos de datos de organismos públicos, o privados destinados a proveer informes, así como la finalidad a que se destine esa información, y a requerir su rectificación, actualización o cancelación. No podrá afectarse el secreto de las fuentes y el contenido de la información periodística.

Ningún dato podrá registrarse con fines discriminatorios ni será proporcionado a terceros, salvo que tengan un interés legitimo. El uso de la informática no podrá vulnerar el honor, la intimidad personal y familiar y el pleno ejercicio de los derechos."

Catamarca: "Art. $11^{\circ}$.- La libertad que antecede [de expresión] comprende el libre acceso a las fuentes de información. Prohíbese el monopolio de la información gubernativa y el funcionamiento de oficinas de propaganda de la labor oficial».

Córdoba: «Art. $50^{\circ}$.- Toda persona tiene derecho a conocer lo que de ella conste en forma de registro, la finalidad a que se destine esa información, y a exigir su rectificación y actualización. Dichos datos no pueden registrarse con propósitos discriminatorios de ninguna clase ni ser proporcionados a terceros, excepto cuando tengan un interés legítimo. La ley reglamenta el uso de la informática para que no se vulneren el honor, la intimidad personal y familiar y el pleno ejercicio de los derechos".

Corrientes: “Art. $184^{\circ}$.- Hasta tanto se dicte la legislación pertinente, se aplicará el régi men de la Ley de Amparo para la efectiva protección inmediata y expeditiva de los derechos y garantias contenidos en las cláusulas operativas de los tratados y convenciones internacionales, que hayan sido objeto de ratificación o adhesión por parte de la República Argentina, sin que puedan incluirse o comprenderse otros reclamos con tal motivon.

Art. $185^{\circ}$.- Mientras no se dicte la ley reglamentaria de una libertad o garantía declarada por esta Constitución y la omisión sea irrazonable, quien se considere afectado por ella en su derecho individual o colectivo podrá solicitar y deberá obrener que la garantía o libertad integre el orden normativo, con efecto limitado a la contienda judicial y al solo fin de decidirla». Chaco: Art. $19^{\circ}$ [...] Toda persona tiene derecho a informarse de los datos que scibre sí mismo, o sobre sus bienes, obren en forma de registros o sistemas oficiales o prividos de carácter público; la finalidad a que se destine esa información, y a exigir su actualización, corrección, supresión o confidencialidad.

Tales datos no podrán ser utilizados con fines discriminatorios de ninguna especie.

No podrá afectarse el secreto de las fuentes de información periodística [...]”.

Chubut: “Art. $56^{\circ}$.- Toda persona puede interponer acción de amparo para tomar conocimiento de los datos a ella referidos y de su finalidad, que consten en registros o bancos de datos públicos o en los privados destinados a proveer informes, y en caso de error, omisión, falsedad o discriminación, para exigir la supresión, rectificación, confidencialidad o actualización de aquéllos. No puede afectarse el secreto de la fuente de información periodística."

Formosa: "Art. $10^{\circ}$.- [...] Todos los habitantes de la Provincia gozan del derecho al libre acceso a las fuentes de información."

Jujuy: “Art. $23^{\circ}$.- [...] 6) Todas las personas tienen derecho de tomar conocimiento de lo que constare a su respecto en los registros provinciales de antecedentes personales y del destino de esas informaciones, pudiendo exigir la rectificación de los datos. Queda prohibido el acceso a terceros a esos registros, así como su comunicación o difusión, salvo en los casos expresamente 
previstos por la ley. [...] 8) El procesamiento de datos por cualquier medio o forma nunca puede ser utilizado para su registro y tratamiento con referencia a convicciones filosóficas, ideológicas o políticas, filiación partidaria o sindical, creencias religiosas o respecto de la vida privada, salvo que se tratare de casos no individualmente identificables y para fines estadísticos".

La Pampa: "Arr. $17^{\circ}$.- Los jueces prestarán amparo a todo derecho reconocido por las Constituciones de la Nación o de la Provincia, y si no hubiere reglamentación o procedimiento legal, arbitrarán a ese efecto trámites breves."

La Rioja: "Art. $30^{\circ}$.- La ley limitará el uso de la informática para preservar el honor, la intimidad personal y familiar de los habitantes y el pleno ejercicio de sus derechos. Las autoridades policiales sólo proporcionarán antecedentes penales de los habitantes en los casos previstos por la ley".

Río Negro: "Art. $20^{\circ}$.- La ley asegura la intimidad de las personas. El uso de información de toda índole o categoría, almacenada, procesada o distribuída por cualquier medio físico o electrónico, debe respetar el honor, la privacidad y el goce completo de los derechos. La ley reglamenta su utilización de acuerdo a los principios de justificación social, limitación de la recolección de datos, calidad, especificación del propósito, confidencialidad, salvaguardia de la seguridad, apertura de los registros, limitación en el tiempo y control público. Asegura el acceso de las personas afectadas a la información para su rectificación, actualización o cancelación cuando no fuera razonable su mantenimientom.

"Art. 26 $6^{\circ}$. [...] Todos los habitantes de la Provincia gozan del derecho del libre acceso a las fuentes públicas de información".

Salta: «Art. $22^{\circ}$. - [...] Las autoridades policiales proporcionan antecedentes penales o judiciales de los habitantes exclusivamente en los casos previstos por la ley».

San Juan: "Art. $26^{\circ}$.- Todo ciudadano tiene derecho a tomar conocimiento de lo que de él conste en forma de registro y de la finalidad a que se destinan las informaciones, pudiendo exigir la rectificación de datos, así como su actualización. No se puede utilizar la informática para el tratamiento de datos referentes a convicciones políticas, fe religiosa o vida privada, salvo cuando se destine para fines estadísticos no identificables».

Art. $27^{\circ}$.- Todos los habitantes tienen derecho a que se les informe veraz y auténticamente sin distorsiones de ningún tipo, teniendo también el derecho al libre acceso a las fuentes de información, salvo en asuntos vitales para la seguridad del Estado. El tiempo de la reserva se fijará por ley. Los registros de antecedentes personales harán figurar en las certificaciones que emitan solamente las causas con condenas no cumplidas contra el interesado, salvo solicitud de autoridad judicial o del mismo interesado. No hay restricción alguna para introducir publicaciones, distribuírlas en el interior de la Provincia, programar, organizar y asistir a congresos de carácter provincial, nacional o internacional. La información en todos sus aspectos es considerada como de interés público".

San Luis: "Art. $21^{\circ}$.- [...] Todos los habitantes de la Provincia tienen derecho a tomar conocimiento de lo que de ellos conste en registros de antecedentes personales e informarse sobre la finalidad a que se destinan dichos registros y la fuente de información en que se obtienen los datos respectivos".

Santa Cruz: "Art. $15^{\circ}$.- "Los jueces prestarán amparo a todo derecho reconocido en la Constitución Nacional y ésta, si no hubiera reglamentación o procedimiento legal, arbitrará a ese efecto trámites breves."

Art. $18^{\circ}$.- Siempre que una ley u ordenanza imponga a un funcionario o corporación pública de carácter administrativo un deber expresamente determinado, todo aquel en cuyo interés deba ejecutarse el acto, o sufriere perjuicio material, moral o político, por falta de cumpli- 
Río Negro, San Luis, San Juan y Tierra del Fuego), aunque con diseños bien diversos.

Además de la regulación constitucional, o en vez de ella, algunas provincias asumieron el tema en la legislación subconstitucional (v.gr., Tucumán y Jujuy).

Así las cosas actualmente en todo el territorio de la nación argentina rige el Art. $43^{\circ}$ de la Constitución nacional (que por su propia formulación es una norma operativa), aunque en coexistencia con algunas regulaciones provinciales.

Tal superposición de regulaciones no ha provocado -aunque podría haberlo hecho- conflictos jurídicos en la práctica, en particular porque el diseño constitucional argentino permite que las provincias establezcan regulaciones más tuitivas de los derechos de los habitantes que las vigentes a nivel federal, siempre que respeten el diseño mínimo establecido por la Constitución nacional, y en todo aquello que regulen de menos respecto de la Carta federal, resultan superadas normativamente ${ }^{18}$.

De tal suerte, el Hábeas Data federal - cuyos alcances están en pleno debate doctrinario y jurisprudencial ${ }^{19}$ - rige en todas las provincias, y en aquellas en las que está regulado, sea a nivel constitucional o subconstitucional, también tienen vigencia tales normas, siempre en todo aquello en que no exista incompatibilidad con la norma federal.

Nos ocuparemos a continuación de establecer las semejanzas y diferencias entre cada regulación local y la federal.

\subsection{Regulación federal}

Al tratar las garantías jurisdiccionales de Amparo, Hábeas Corpus y Hábeas Data, el Art. $43^{\circ}$ de la Constitución argentina establece, en su

miento del deber, puede demandar ante los Tribunales su ejecución inmediata y el Tribunal, previa comprobación sumaria de la obligación legal y del derecho del reclamante, dirigirá al funcionario o corporación un mandamiento de ejecución".

Tierra del Fuego: "Art. $45^{\circ}$.- Toda persona tiene derecho a conocer lo que de ella conste en forma de registro y la finalidad a que se destine esa información, $y$ a exigir su rectificación y actualización. Esos datos no pueden registrarse con propósitos discriminatorios de ninguna clase, ni ser proporcionados a terceros, excepto cuando éstos tengan un interés legítimo".

18 Esta conclusión parte del propio diseño de la Constitución argentina, en la cual las provincias han delegado en el Estado federal más poder para regular las relaciones civiles que la Constitución norteamericana, sin duda su fuente más relevante.

19 Ver al respecto el trabajo de Néstor P. Sagués: Derecho Procesal Constitucional. Acción de amparo, Astrea, Buenos Aires, 1996, cap. XXVII. 
tercer párrafo, que "Toda persona podrá interponer esta acción (la de amparo, regulada por los dos párrafos anteriores) para tomar conocimiento de los datos a ella referidos y de su finalidad, que consten en registros o bancos de datos públicos, o los privados destinados a proveer informes, y en caso de falsedad o discriminación, para exigir la supresión, rectificación, confidencialidad o actualización de aquéllos. No podrá afectarse el secreto de las fuentes de información periodística».

La norma, como fuera mencionado, no fue objeto de reglamentación, aunque tal proceso se encuentra avanzado, pues el 27 de noviembre de 1996, el Congreso de la Nación sancionó el proyecto de ley $n^{\circ}$ 24.745 (que incluía una primera parte donde regulaba aspectos relativos al tratamiento de datos personales en general y también el Hábeas Data), que fue vetado en su totalidad por el Poder Ejecutivo el 23 de diciembre de 1996, remitiendo a las Cámaras una iniciativa propia al respecto, que aún no ha sido objeto de tratamiento legislativo.

\subsection{Regulaciones estaduales}

\subsubsection{Ciudad Autónoma de Buenos Aires}

La reforma constitucional federal argentina de 1994 creó la nueva figura de la "Ciudad Autónoma de Buenos Aires", donde geográficamente se asienta la Capital Federal. Este nuevo Estado goza de un status constitucional especial, asimilado a una provincia ${ }^{20}$.

A partir de esta prescripción constitucional, en 1996 se dictó un peculiar Estatuto-Constitución (o en los propios términos de su Preámbulo, una "Constitución como estatuto organizativo de la Ciudad de Buenos Aires"), que reprodujo similarmente las acciones jurisdicciona-

20 En este sentido, el nuevo Art. $129^{\circ}$ de la Constitución nacional es el producto de una cláusula parcialmente insertada en el "Pacto de Olivos" (que sirviera de preludio para la reforma constitucional), y, como explica Sagüés, citando a García Lema, Dromi y Menem, trae como consecuencia que la ciudad de Buenos Aires goce ahora de un status constitucional especial, ya que es más que un municipio -al tener explíciros poderes de legislación y jurisdicción- pero menos que una provincia, aunque a veces se asimila a una de ellas. Es, en verdad, una semiprovincia o cuasi provincia, cuyo territorio está íntegramente federalizado conforme al Art. 3" de la Constitución federal (Néstor P. Saguiés, Introducción y comentario a la Constitución de la Ciudad Autónoma de Buenos Aires, Astrea, Buenos Aires, 1996, pp. 23 y 24 ). 
les de garantía pergeñadas por el constituyente nacional dos años antes (Arts. $14^{\circ}$ a $16^{\circ}$ ).

Así, en lo que respecta al Hábeas Data, el Art. $16^{\circ}$ de la Carta Fundamental establece que:

"Toda persona tiene, mediante una acción de amparo, libre acceso a todo registro, archivo o banco de datos que conste en organismos públicos o en los privados destinados a proveer informes, a fin de conocer cualquier asiento sobre su persona, su fuente, origen, finalidad o uso que del mismo se haga".

También puede requerir su actualización, rectificación, confidencialidad o supresión, cuando esa información lesione o restrinja algún derecho.

El ejercicio de este derecho no afecta el secreto de la fuente de información periodística."

Poco antes, el Art. $13^{\circ}$ Inc. 8 -al tratar la libertad física-, establece que el secuestro de papeles, correspondencia e información personal almacenada sólo pueden ser ordenados por el juez competente ${ }^{21}$.

Como se verá, el tratamiento de la información personal recibe en este caso, una tutela especial.

El Hábeas Data es considerado un subtipo de amparo, y contiene ciertas precisiones que no se observan en la norma nacional.

Por ejemplo, respecto del primer tramo del Hábeas Data, el Art. $16^{\circ}$ del Estatuto-Constitución alude al "libre acceso" al lugar donde se encuentran los datos (la norma nacional habla sólo de "conocer" lo que conste registrado, lo que no es necesariamente lo mismo).

De otro lado, la norma local no sólo alude a conocer el asiento que se haya realizado sobre su persona, sino además su fuente, origen, finalidad o uso (el Art. $43^{\circ}$ de la Constitución sólo refiere a conocer el dato y su finalidad), pero siempre con el coto que significa, al igual que en la norma nacional, que el ejercicio de este derecho no puede afectar el secreto de la fuente de información periodística.

Con relación al segundo tramo -esto es, una vez conocidos los datos, qué puede hacerse con ellos-, la norma toma casi textualmente los

21 Poco después, en el Arr. $43^{\circ}$-al ocuparse de la tutela de consumidores y usuariosestablece que éstos tienen derecho de acceder a la información transparente, adecuada y veraz. 
objetivos expresados en la Constitución nacional (actualización, rectificación, confidencialidad o supresión).

Finalmente, en una extensión más generosa que la establecida en la norma nacional, para el funcionamiento del Hábeas Data no requiere que exista falsedad del dato o discriminación del registrado, pues sólo es necesario, para que la garantía opere, que esa información "lesione o restrinja algún derecho".

\subsubsection{Provincia de Buenos Aires}

En la provincia de Buenos Aires, el Art. 20 $0^{\circ}$, Inc. 3 de la Constitución (reformada en 1994), consagra al Hábeas Data dentro de las garantías jurisdiccionales -no la trata como subtipo de amparo-, remitiendo todo lo relativo a su procedimiento a una futura ley reglamentaria, pero aclarando que se trata de una norma operativa, y que en ausencia de reglamentación, los jueces deben resolver sobre la procedencia de las acciones que se promuevan en consideración a la naturaleza de los derechos que se pretendan tutelar.

En cuanto al sujeto activo, al igual que la norma nacional, la Constitución provincial refiere a "toda persona" respecto de la cual consten datos, sin hacer distinciones.

Lo mismo ocurre con relación al sujeto pasivo, ya que alude a todo registro, archivo o banco de datos de organismos públicos, o privados destinados a proveer informes.

Con respecto a los derechos que se conceden al registrado, son prácticamente los mismos que los reconocidos en la norma nacional, pues refiere al conocimiento de los datos, de la finalidad a que se destine esa información, y a requerir su rectificación, actualización o cancelación, e incluso la confidencialidad ${ }^{22}$.

Prohíbe luego el registro de datos con fines discriminatorios - claramente prohibidos por la norma nacional- y coincide en que no podrá afectarse el secreto de las fuentes de la información periodística, aunque extiende la prohibición al contenido mismo de la información.

22 Si bien no menciona la palabra "confidencialidad", de todas maneras dice que los datos no podrán proporcionarse a terceros, salvo que tengan un interés legítimo, lo que es lo mismo. 
Finalmente, en lo que puede entenderse como una cláusula que permite una amplia tutela y supera en tal sentido a la norma nacional -aunque confunde Hábeas Data con informática一, la norma local, siguiendo el esquema trazado por el Art. $18^{\circ}$ de la Constitución Española, aclara finalmente que el uso de la informática no podrá vulnerar el honor, la intimidad personal y familiar y el pleno ejercicio de los derechos, pero no dice - aunque bien podría sobreentenderse- que tampoco puede producirse esta vulneración por registros no informatizados.

\subsubsection{Provincia de Catamarca}

En lo que a este trabajo atañe, el Art. $11^{\circ}$ de la Constitución catamarqueña establece en primer lugar que la libertad de expresión comprende el libre acceso a las fuentes de información y luego prohibe el monopolio de la información gubernamental.

Si bien la norma no regula el Hábeas Data, lo cierto es que alude a uno de los derechos de los productores de datos, cual es el de recabar la información, prohibiendo, como lógica consecuencia de lo anterior, el monopolio informativo.

De esta forma se asegura tanto los derechos de los particulares, como la libertad de expresión, que se traduce lógicamente en la libertad de prensa y se proyecta en tutela del orden democrático.

La prohibición del monopolio de la información gubernamental tiende también al mismo objetivo, y a su vez evita la manipulación de dicha información -oficial o privada-, que puede provocar no sólo la distorsión de ésta, originando desigualdades de todo tipo, sino también el indebido acceso a información relativa a las personas.

\subsubsection{Provincia de Córdoba}

El Art. $50^{\circ}$ de la Constitución cordobesa regula al Hábeas Data. Es una norma anterior a la reforma constitucional nacional y padece de algunos aspectos objetables.

En primer lugar, cuando establece que "toda persona tiene derecho a conocer lo que de ella conste en forma de registro", abre el camino a diferentes interpretaciones, de suerte tal que, según como se interprete la palabra "registro", puede o no avanzar indebidamente sobre derechos y libertades de terceros. 
Si se trata de un sinónimo de "asiento" (según la terminología del Estatuto-Constitución de la Ciudad Autónoma de Buenos Aires) o de un "lugar donde se producen anotaciones", podría verificarse una incursión en la intimidad del registrador, y consecuentemente resultaría inconstitucional acceder a cualquier sitio donde figuren datos personales (v.gr., un ordenador), pues mientras ese lugar donde se anota ese asiento no trascienda, o no esté preparado para trascender más allá de quien es su titular o de quien lo asentó, se encuentra protegido por la cláusula constitucional que establece la inviolabilidad de los papeles privados.

Si la palabra "registro", por el contrario, se refiere a un "sitio u oficina donde se registra" cuya función específica es la de recabar información de terceros con una aptitud para trascender a otras personas distintas de quien recepta los datos, entonces sí parece atinado que se otorgue el derecho a conocer los datos personales registrados.

Hecha esta salvedad, resulta coherente - y ello a su vez empalma con lo establecido a nivel federal- que se exija la determinación por parte del registrador respecto de la finalidad a que se destina esa información. Lo mismo ocurre con el derecho a exigir su rectificación y actualización.

La prohibición de registrar datos con propósitos discriminatorios es coherente, aunque innecesaria, pues de hecho ello es ilegal a la luz de la Constitución nacional y la local, además de los pactos internacionales sobre derechos humanos ratificados por la Argentina incluídos aquellos que ostentan jerarquía constitucional conforme lo establecido en el Art. $75^{\circ}$ Inc. 22 de la Carta federal.

La misma suerte corre la prohibición de que los datos sean proporcionados a terceros excepto cuando tengan un interés legítimo, aunque coincide con el derecho a obtener la confidencialidad de los datos establecido en el Art. $43^{\circ}$ de la Constitución nacional.

Con relación a la disposición final que alude a que la ley reglamentará el uso de la informática para que no se vulneren el honor, la intimidad personal y familiar y el pleno ejercicio de los derechos, es una regla plausible, pero tal vez hubiera merecido otra ubicación, pues no se refiere específicamente al Hábeas Data, sino al derecho informático en general, del cual el Hábeas Data es una minúscula -aunque importante- parte. 
Esta norma ha sido observada en ciertos aspectos por alguna doctrina, y como bien se ha dicho: "Se advierte claramente por la redacción que las personas jurídicas se hallan excluidas - no estamos de acuerdo con ello porque en la norma se legitima a "toda persona"-, que la cancelación de datos no ha sido prevista (aunque se aplica la norma nacional) y la misma confusión informática que se produjo en la norma bonaerense"23.

\subsubsection{Provincia de Corrientes}

Si bien la Constitución correntina no regula al Hábeas Data, trae dos cláusulas abiertas (Arts. $184^{\circ}$ y $185^{\circ}$ ) que permiten su construcción doctrinaria y jurisprudencial.

El primero de los artículos mencionados establece que se aplicará el régimen de la Ley de Amparo para la efectiva protección inmediata y expeditiva de los derechos y garantías contenidos en las cláusulas operativas de los tratados y convenciones internacionales, que hayan sido objeto de ratificación o adhesión por parte de la República Argentina.

Para extraer al Hábeas Data de allí, basta con encontrar un derecho lesionado cualquiera por la manipulación de datos y aplicarle el régimen del amparo - del cual el Hábeas Data es un subtipo especializado-. Nada más, y nada menos.

La disposición analizada se complementa y refuerza con la posibilidad apuntada por el Art. $185^{\circ}$, cuando establece que mientras no se dicte la ley reglamentaria de una libertad o garantía declarada por la Constitución y la omisión sea irrazonable, quien se considere afectado por ella en su derecho individual o colectivo podrá solicitar y deberá obtener que la garantía o libertad integre el orden normativo, con efecto limitado a la contienda judicial y al solo fin de decidirla.

Si bien esta construcción parecía de suma utilidad con anterioridad a la reforma constitucional nacional de 1994 ante la falta de regulación federal, tal modificación no la torna ahora inútil, porque el Art. $43^{\circ}$ de la Constitución federal establece un perfil de Hábeas Data que tiene sus límites, y como ya se ha dicho, bien podría crearse en el ámbito provincial una figura más generosa a partir de las disposiciones precitadas.

23 Enrique M. Falcón: Hábeas Data. Concepto y procedimiento. Abeledo Perror, Buenos Aires, 1966, p. 33. 


\subsubsection{Provincia del Chaco}

El Art. $19^{\circ}$ de la Carta chaqueña regula expresamente al Hábeas Data de una manera bastante detallada y similar a lo dispuesto en el orden federal.

En primer lugar, estipula que toda persona tiene derecho a informarse de los datos que obren registrados sobre sí mismo, o sobre sus bienes. El agregado referido a los bienes se incluyó para disipar las dudas sobre si sólo los datos relativos a la persona incluía o no aspectos patrimoniales (aunque para nosotros se encuentra comprendido en los datos de índole personal), indudable aunque implícitamente contemplados en el Art. $43^{\circ}$ de la Constitución nacional.

Con relación al sujeto pasivo, la norma alude a los registros o sistemas oficiales o privados de carácter público, con una terminología que, si bien distinta, se acerca conceptualmente a la norma federal.

Con respecto al objeto de la garantía, establece —además del derecho de informarse acerca de los datos- que el registrado puede conocer la finalidad a que se destine esa información, y también exigir su actualización, corrección, supresión o confidencialidad. En esto sigue al pie de la letra a la Carta federal.

Lo mismo ocurre cuando establece que los datos no podrán ser utilizados con fines discriminatorios de ninguna especie y que no podrá afectarse el secreto de las fuentes de información periodística.

Finalmente la norma declara su operatividad y la necesaria adecuación de las normas procesales vigentes mientras no sea dictada una ley reglamentaria, y establece sanciones a los jueces y funcionarios que omitan aplicarla directamente.

Si bien acordamos con Falcón en que la garantía - al menos en su literalidad - se exriende a los bienes y se establecen sanciones para el caso de incumplimiento de órdenes judiciales, no nos parece que la no especificación de las personas jurídicas como sujetos legitimados lleve inexorablemente a considerar que en esta provincia se limita el derecho a las personas físicas ${ }^{24}$.

24 Enrique M. Falcón: Hábeas Data. Concepto y procedimiento. Abeledo Perrot, Buenos Aires, 1966, p. 33. 


\subsubsection{Provincia del Chubut}

El Art. $56^{\circ}$ de la Constitución del Chubut regula expresamente al Hábeas Data con una técnica casi idéntica a la de la norma federal, cuando establece que: "Toda persona puede interponer acción de amparo para tomar conocimiento de los datos a ella referidos y de su finalidad, que consten en registros o bancos de datos públicos o en los privados destinados a proveer informes, y en caso de error, omisión, falsedad o discriminación, para exigir la supresión, rectificación, confidencialidad o actualización de aquéllos. No puede afectarse el secreto de la fuente de información periodística.»

La única variante que se advierte es que se agregan las palabras "error" y "omisión" para caracterizar la conducta lesiva del sujeto pasivo del Hábeas Data, ampliando así el espectro protectivo de la norma a otros supuestos, ya que error no necesariamente equivale a falsedad, y una omisión puede provocar distintos efectos (entre ellos, la discriminación).

\subsubsection{Provincia de Formosa}

La Constitución formoseña no ha incorporado la figura del Hábeas Data, pero en su Art. $10^{\circ}$ se ocupa de establecer que todos los habitantes de la provincia gozan del derecho al libre acceso a las fuentes de información, regulando así aspectos relativos a la actividad del colector de datos.

\subsubsection{Provincia de Jujuy}

El Art. $23^{\circ}$ de la Constitución jujeña establece, en su Inc. 6, que todas las personas tienen derecho de tomar conocimiento de lo que constare a su respecto en los registros provinciales de antecedentes personales y del destino de esas informaciones, pudiendo exigir la rectificación de los datos.

Esto abre la perspectiva de un Hábeas Data con un sujeto pasivo reducido al campo oficial y de un derecho - también restringido- a la mera rectificación de datos. Sin embargo, la operatividad de la norma federal supera normativamente a esta previsión, con lo cual debe ampliarse la protección a los registros o bancos de datos privados des- 
tinados a proveer informes, y los derechos de los registrados, a los demás establecidos en el orden nacional.

La ulterior prohibición de acceso de terceros a esos datos, así como de su comunicación o difusión salvo en los casos expresamente previstos por la ley, constituye una explicitación del principio de confidencialidad regulado por la norma federal.

Pasando al Inc. 8 del citado Art. $23^{\circ}$, éste incursiona en un terreno bastante trabajado por la doctrina, cual es el relativo a la "información sensible", cuando establece: "El procesamiento de datos por cualquier medio o forma nunca puede ser utilizado para su registro y tratamiento con referencia a convicciones filosóficas, ideológicas o políticas, filiación partidaria o sindical, creencias religiosas o respecto de la vida privada, salvo que se tratare de casos no individualmente identificables y para fines estadísticos".

Pese a la evidente buena intención del constituyente, esta norma puede pecar de inconstitucionalidad en el caso concreto, pues resulta obvio que algunos sujetos se encuentran razonablemente habilitados para tratar los datos previamente mencionados (v. gr., filiación partidaria, por ciertos registros electorales, o creencias religiosas, por los registros nacionales de cultos, etc.).

En esta provincia, se ha dictado una ley que establece el "amparo de Hábeas Data". Explica Sagüés al comentarla, que:

"la reciente Ley $\mathrm{N}^{\circ} 4444$ de Jujuy reglamenta la publicidad de los actos de gobierno y el libre acceso a la información del Estado $[\ldots]$.

Ahora bien, el Art. $12^{\circ}$ establece el amparo de Hábeas Data, al disponer que "al solo efecto de satisfacer su necesidad informativa denegada -expresa o tácitamente- por autoridad competente, el afectado podrá recurrir en amparo de su derecho ante el organismo judicial competente, de acuerdo a lo previsto por la Constitución de la provincia (Arts. $39^{\circ}, 41^{\circ}$ y concs.) y conforme al régimen procesal en la materia (Ley $\mathrm{N}^{\circ} 4442$ ).

En concreto, la ley en cuestión no crea un nuevo régimen procesal de amparo, sino que especifica o aplica el amparo vigente (Ley $\mathrm{N}^{\circ} 4442$ ) al caso del ejercicio del derecho a informarse. La metodologia parece correcta: no se trata de multiplicar las 
acciones de amparo, sino de proyectar la existencia de amparo a la realización de un derecho constitucional" 25 .

Comentando ambas normas, expresa Falcón con respecto a la Constitución nacional, "se agrega la excepción al Hábeas Data por vía estadística impersonal, y claramente expone la prohibición de usar el procesamiento de datos (por vía informática o cualquier otra) de modo discriminatorio. Además en esta provincia se dictó una ley reglamentaria, la $\mathrm{N}^{\circ} 4444$, que en su artículo $10^{\circ}$ dispone que el derecho de libre acceso a las fuentes de información pública puede ejercerlo toda persona física o jurídica, radicada en la provincia, sin que sea necesario indicar las razones que lo motivan, y de esta manera clarifica la legitimación por un lado y se extiende claramente la procedencia del recurso ${ }^{26}$.

\subsubsection{Provincia de La Rioja}

Si bien la Constitución riojana no regula al Hábeas Data puntualmente, su Art. $30^{\circ}$ reconoce los problemas que para los derechos de las personas involucradas en el tratamiento de datos ocasiona a la informática en general, y consecuentemente estipula que la ley limitará el uso de la informática para preservar el honor, la intimidad personal y familiar de los habitantes y el pleno ejercicio de sus derechos.

Establece además la confidencialidad de ciertos datos, al mencionar que las autoridades policiales sólo proporcionarán antecedentes penales de los habitantes en los casos previstos por la ley.

\subsubsection{Provincia de La Pampa}

El Art. $17^{\circ}$ de la Constitución pampeana establece que los jueces prestarán Amparo a todo derecho reconocido por las constituciones de la nación o de la provincia, "y si no hubiere reglamentación o procedimiento legal, arbitrarán a ese efecto trámites breves".

25 Néstor P. Saguiés: Derecho Procesal Constitucional. Acción de amparo, Ascrea, Buenos Aires, 1996, ps. 665/6.

26 Enrique M. Falcón: Hábeas Data. Concepto y procedimiento. Abeledo Perrot, Buenos Aires, 1966 , p. 35. 
Esta disposición obviamente es utilizable para el caso del Hábeas Data, cuando, conforme a las pautas atributivas de competencia, corresponda intervenir a la justicia provincial.

\subsubsection{Provincia de Río Negro}

La Constitución rionegrina de 1988 reguló expresamente al Hábeas Data -sin llamarlo así- en su Art. $20^{\circ}$ y dentro de un esquema de protección general a los datos personales adopta los diez principios comunes a las primeras normas europeas sobre datos personales:

a) el de la justificación social, según el cual la recolección de datos debe tener un propósito general y usos específicos socialmente aceptables;

b) el de limitación de la recolección, el cual estatuye que los datos deben ser obtenidos por medios lícitos, es decir, con el conocimiento y consentimiento del sujeto de los datos o con autorización legal, y limitarse al mínimo necesario para alcanzar el fin perseguido por la recolección;

c) el de calidad o fidelidad de la información, que implica la obligación de conservar los datos exactos, completos y actuales;

d) el de especificación del propósito o la finalidad, para que los datos no sean usados con fines diferentes;

e) el de confidencialidad, conforme al cual el acceso de terceros a los datos debe tener lugar con el consentimiento del sujeto o con autorización legal;

f) el de salvaguarda de la seguridad, por el cual el responsable del registro de datos personales debe adoptar medidas adecuadas para protegerlos contra posibles pérdidas, destrucciones o acceso no autorizado;

g) el de política de apertura, que implica asegurar el conocimiento, por parte del público, de la existencia, fines, usos y métodos de operación de los registros de datos personales;

h) el de limitación en el tiempo, que entraña su conservación hasta que sean alcanzados los fines perseguidos;

i) el de control público, que implica la necesaria existencia de un organismo responsable de la efectividad de los principios contenidos en la legislación;

j) el de participación individual, que consagra el derecho de acceso a los datos y los derechos conexos. 
Por cierto que la mayoría de estos principios son jurídicamente inobjetables, pero otros denotan un excesivo intervencionismo.

Así, si al principio de limitación de la recolección - que requiere el consentimiento del sujeto para la incorporación de cada dato--, se lo llevara a la práctica en forma estricta, se condenaría a los bancos de datos a la desaparición.

De otro lado, la limitación en el tiempo también es objetable, pues puede ocurrir que datos que hoy ya no son útiles mañana lo sean, con lo cual, en principio, no tiene sentido su destrucción. Finalmente, la imposibilidad de uso de los datos recolectados con otros fines distintos a los que motivaron su recolección también parece un exceso, pues la alternativa de que fructifiquen en otros aspectos, si no se trata de datos que deban ser mantenidos en confidencialidad o que puedan perjudicar a sus registrados, nos parece objetable.

Además de la disposición precedentemente analizada, cabe mencionar que el Art. $26^{\circ}$ de la Carta, al igual que varias similares de otras provincias, establece que todos los habitantes de la Provincia gozan del derecho del libre acceso a las fuentes públicas de información.

\subsubsection{Provincia de Salta}

Si bien la Constitución salteña no regula el Hábeas Data, se ocupa de establecer, en su Art. $22^{\circ}$, el principio de confidencialidad de ciertos datos recabados por la Administración pública, cuando menciona que las autoridades policiales proporcionan antecedentes penales o judiciales de los habitantes exclusivamente en los casos previstos por la ley.

\subsubsection{Provincia de San Juan}

La Carta sanjuanina posee dos disposiciones vinculadas con el tema que nos ocupa.

En primer lugar, su Art. $26^{\circ}$ se ocupa de regular el Hábeas Data cuando concede a todo ciudadano el derecho a tomar conocimiento de lo que de él conste en forma de registro y de la finalidad a que se destinan las informaciones, pudiendo exigir la rectificación de datos, así como su actualización.

Esta primera parte de la norma padece de ciertas deficiencias, que obviamente son superadas normativamente por la Carta federal. 
Entre ellas, cabe mencionar, por un lado, que al aludir a "todo ciudadano", excluye a las personas jurídicas, que no pueden ostentar tal carácter. Por el otro, el derecho a tomar conocimiento de lo que conste en forma de registro sobre su persona puede resultar excesivo, como ya lo expresamos con anterioridad, si se entiende por registro cualquier asiento de dato, sin importar su titular (podría en este sentido, vulnerarse la inviolabilidad de los papeles privados del registrador).

El derecho a conocer la finalidad del registro no presenta problemas, pero los derechos de rectificación y de actualización son insuficientes frente a la norma federal, que la supera expresamente en los derechos de cancelación y confidencialidad.

La parte final del artículo, al prohibir el uso de la informática para el tratamiento de datos referentes a convicciones políticas, fe religiosa o vida privada, salvo cuando se destine para fines estadísticos no identificables, si bien tiene una finalidad loable, peca por defecto, pues como ya fuera explicado, ciertos organismos pueden, natural y legítimamente, tratar algunos de esos datos.

De otro lado, el Art. $27^{\circ}$ alude al derecho a la información veraz y al libre acceso a las fuentes de información, con la excepción de los asuntos vitales para la seguridad del Estado, punto que actualmente se discute si es aplicable o no como causal de restricción al Hábeas Data.

Luego menciona que el tiempo de la reserva se fijará por ley, y regula la forma de registro de los antecedentes penales, autorizando a que se haga constar solamente las causas con condenas no cumplidas contra el interesado, salvo solicitud de autoridad judicial o del mismo interesado.

Finalmente, menciona que la información en todos sus aspectos es considerada como de interés público.

Al comentar la norma, explica Falcón que: "En primer lugar el artículo $26^{\circ}$ en su primera parte acierta cuando utiliza la palabra "registro" en sentido general (sin necesidad de hacer una enumeración taxativa de archivos, bancos de datos, etc.), aunque este artículo y toda su normativa está exclusivamente destinado a las personas físicas [...]. Luego, al igual que la Constitución de la provincia de Buenos Aires confunde el Hábeas Data con la informática [...]" ${ }^{27}$.

27 Enrique M. Falcón: Hábeas Data. Concepto y procedimiento. Abeledo Perrot, Buenos Aires, 1966, p. 37. 


\subsubsection{Provincia de San Luis}

La carta de esta provincia consagra, en su Art. $21^{\circ}$, algunos aspectos del Hábeas Data, al establecer que todos los habitantes de la Provincia tienen derecho a tomar conocimiento de lo que de ellos conste en registros de antecedentes personales e informarse sobre la finalidad a que se destinan dichos registros y la fuente de información de la que se obtienen los datos respectivos.

Como se observará, al aludir a "habitante", limita a la legitimación activa a las personas físicas, y al otorgar solamente el derecho a conocer los datos, la fuente de información y la finalidad de los registros, se queda a mitad de camino, pues resulta obvio que le faltó establecer qué más puede hacer el registrado si se produce alguna violación de sus derechos por la actividad reseñada.

Al analizar esta regulación, indica Falcón que "la limitación a la persona física por un lado, los registros privados excluídos y la falta de previsión sobre las fuentes de información periodística son tres errores de esta norma $[\ldots]^{\prime 28}$.

\subsubsection{Provincia de Santa Cruz}

El Art. $15^{\circ}$ de la Constitución santacruceña -de manera similar que la pampeana- ordena a los jueces prestar Amparo a todo derecho reconocido en la Constitución Nacional y establece que si no hubiera reglamentación o procedimiento legal, arbitrará a ese efecto trámites breves.

Resulta tal vez obvio expresar que cuando se demande en la justicia provincial por vía de Hábeas Data, se debe recurrir a esta norma para su articulación.

\subsubsection{Provincia de Tierra del Fuego, Antártida e Islas del Atlántico Sur}

El Art. $45^{\circ}$ de la carta fueguina se ocupa puntualmente del Hábeas Data, aunque también peca por defecto por cuanto sólo adjudica a toda persona el derecho a conocer lo que de ella conste en forma de

28 Enrique M. Falcón: Hábeas Data. Concepto y procedimiento. Abeledo Perror, Buenos Aires, 1966, p. 38. 
registro -reiteramos aquí que podría colisionar con la inviolabilidad de los papeles privados de su registrador- $y$ la finalidad a que se destine esa información.

Cuando establece que la persona perjudicada puede exigir su rectificación y actualización, peca de mezquina, pues no previó el derecho de cancelación, que ahora sí está contemplado en la norma federal.

La facultad de confidencialización se esboza al final de la segunda parte del artículo, cuando dice que esos datos no pueden registrarse con propósitos discriminatorios de ninguna clase, ni ser proporcionados a terceros, excepto cuando éstos tengan un interés legítimo.

\subsubsection{Provincia de Tucumán}

Si bien la carta tucumana no alude al Hábeas Data, bien ha señalado Falcón que sobre la base del proyecto Díaz Ricci se ha elaborado un Código Procesal Constitucional, que regula el Hábeas Data como una especie del amparo-reglado por el artículo $34^{\circ}$ de la Constitución provincial- sin distinguir si el acto es del poder público o de particulares $^{29}$.

\section{Reevaluación}

De las normas revisadas podemos observar que, de la misma forma que las garantías de rectificación y respuesta (ambas aristas del mal rotulado derecho de réplica, y subtipos de amparo) apuntan fundamentalmente a proteger el honor, la reputación y la propia imagen -e incluso para algunos también los derechos a la identidad y a la intimidad-, la acción de Hábeas Data puede proteger uno o más derechos.

Sin embargo, por lo general, las normas constitucionales sobre protección de datos personales y Hábeas Data han limitado su radio de acción aludiendo no a derechos tutelados sino a tipos de datos tratados, como los relativos a la fe religiosa, a las convicciones políticas y a la vida privada (Portugal y San Juan); al honor y la intimidad (España); a la intimidad personal y familiar y al buen nombre (Colombia); a la

29 Enrique M. Falcón: Hábeas Data. Concepto y procedimiento. Abeledo Perrot, Buenos Aires, 1966 , p. 38. 
filiación política (Guatemala); al honor, la intimidad personal y familiar y el pleno ejercicio de los derechos (provincia de Buenos Aires, Córdoba, La Rioja y Río Negro).

Otras optan por referir a aquellos datos que sean falsos (provincia de Buenos Aires y Chubut), erróneos (Chubut), omisivos (Chubut) o que tengan por finalidad discriminar (Buenos Aires, Chaco y Chubut), siguiendo la línea trazada por la reforma constitucional argentina de 1994.

En el caso de la Ciudad Autónoma de Buenos Aires, se precisa mejor la cuestión, definiendo que el Hábeas Data funciona cuando la información lesione o restrinja algún derecho.

En el orden federal argentino, la norma prefiere no enunciar ninguno de estos supuestos y, por el contrario, tutela los casos de falsedad o discriminación, con lo que la deja abierta a una amplia gama de bienes a proteger, aunque no iguala en amplitud a la disposición de la Ciudad Autónoma de Buenos Aires.

Con respecto a la protección constitucional de la actividad del registrador, varias constituciones provinciales se han encargado de destacar el derecho de libre acceso a las fuentes de información (Catamarca, Chaco, Formosa, Río Negro, San Luis y San Juan), pero este principio goza, también en el normativo, de excepciones expresas, como en el caso de los asuntos vitales para la seguridad del Estado (San Juan).

Algunas normas suelen admitir una mayor amplitud en el registro cuando los datos están destinados a fines estadísticos no identificables (Portugal, Jujuy y San Juan), o cuando atañen a la propia actividad del registrador, como en el caso de los datos de filiación política, que pueden ser almacenados por las autoridades electorales y de los partidos políticos (Guatemala).

Las normas constitucionales sobre Hábeas Data dan, a veces, un marco para que luego el Legislativo las reglamente (v. gr., España). Otras veces son más reglamentaristas y le dan un perfil más definido al instituto, estableciendo derechos concretos de los registrados (v. gr., Portugal, Brasil, Colombia, Paraguay, Buenos Aires -Ciudad Autónoma y provincia-, Córdoba, Chaco, Chubut, Río Negro y Tierra del Fuego).

Los derechos que en general mencionan son variados, pero podríamos distinguirlos en dos etapas. La primera, relativa al acceso, que presenta algunas complicaciones cuando se pretende su restricción por 
motivos excepcionales (seguridad del Estado, libertad de prensa, etc.) y la segunda, que consistirá, básicamente, en el control de los datos a los que se accedió y la consecuente modificación, exclusión o confidencialización de ellos, si existe violación a algún derecho.

En cuanto al acceso a los datos propios, dicha potestad está generalmente contenida en forma expresa de dos maneras, como potestad de acceder al registro o como derecho a conocer los datos (Portugal, Brasil, Colombia, Guatemala, Paraguay, Buenos Aires -Ciudad Autónoma y provincia- Corrientes Chaco, Chubut, Jujuy, San Luis, San Juan y Tierra del Fuego). En algunos casos, tal potestad puede ser limitada por vía del sujeto que puede solicitarla, por vía del registro al cual se puede acceder, o por vía del motivo de la registración.

Otra restricción que estaría basada no en el acceso al banco sino en el acceso a la fuente que proporcionó ese dato, es el relativo a las fuentes de información periodística, las cuales están expresamente protegidas, no sólo en el texto constitucional nacional, sino también en algunas constituciones provinciales (Buenos Aires -Ciudad Autónoma y provincia-, Chaco y Chubut), que en el caso de la provincia de Buenos Aires se extiende también al contenido mismo de la información periodística.

Respecto del sujeto activo del Hábeas Data, esto es, el sujeto que puede solicitar el acceso, las normas revistadas incluyen distintas versiones: algunas lo prevén para toda persona registrada -que incluiría a las físicas y jurídicas- (Brasil, Guatemala, Paraguay, Perú, Colombia, Buenos Aires -Ciudad Autónoma y provincia-, Chaco, Chubut, Jujuy y Tierra del Fuego), y otras se refieren a los ciudadanos (España, Portugal, San Juan) o a los habitantes (Formosa, La Rioja, Río Negro y San Luis).

En relación con el sujeto pasivo o registro al cual se puede acceder, algunas constituciones establecen un derecho amplio, que abarca a toda autoridad, funcionario o persona (Perú); a los bancos de datos y archivos de entidades públicas y privadas (Colombia); a lo que conste en forma de registro (Córdoba, Río Negro, San Luis, San Juan y Tierra del Fuego); a los registros o bancos de datos públicos o los privados destinados a proveer informes (Chubut), y a todo registro, archivo o bancos de datos de organismos públicos, o privados destinados a proveer informes (Buenos Aires -Ciudad Autónoma y provincia-). Empero, otras lo restringen a los registros estatales (Guatemala), a los registros oficia- 
les o privados de carácter público (Paraguay y Chaco) y a los registros provinciales de antecedentes personales (Jujuy).

Por cierto que, como ya lo advertimos, una excesiva amplitud en cuanto a la legitimación pasiva acarrearía como consecuencia que pudieran violarse derechos del registrador de carácter constitucional, ante ficheros, registros o anotaciones de carácter personal.

En cuanto a los derechos que se concede ante datos inexactos, el registrado tendrá derecho a la actualización de aquellos que se hubieren tornado vetustos (Portugal, Colombia, Paraguay, Buenos Aires -Ciudad Autónoma y provincia-. Corrientes, Chaco Chubut, San Juan y Tierra del Fuego), o a la rectificación de los datos que fueran incorrectos (Portugal, Brasil, Colombia, Paraguay, Buenos Aires - Ciudad Autónoma y provincia-, Córdova, Chaco, Chubut. Jujuy, San Juan y Tierra del Fuego).

En el caso de datos que, por sus características, no deben estar registrados, corresponde otorgar el derecho a la exclusión, supresión o cancelación (Paraguay, Buenos Aires -Ciuidad Autónoma y provincia-, Chaco y Chubut), y si, por el contrario, ellos están legítimamente registrados, pero no deben ser conocidos por cualquier tercero sino sólo por algunos en determinadas circunstancias (como en la hipótesis de información que esté cubierta por el secreto fiscal, bancario o médico), se debe reconocer el derecho a la confidencialidad (Buenos Aires -Ciudad Autónoma y provincia-, Córdoba, Chaco, Chubut, Jujuy y Tierra del Fuego).

Estos dos últimos derechos pueden ser ejercidos también cuando, pese a no estarse en presencia de datos de registración prohibida, la finalidad del registro fuera ilícita (v.gr., propósitos discriminatorios). En este sentido, varias normas establecen el control de la finalidad, propósito o destino (Portugal, Guatemala, Paraguay, Buenos Aires Ciudad Autónoma y provincia-, Córdoba, Chaco, Chubut, Río Negro, San Luis, San Juan y Tierra del Fuego) ${ }^{30}$.

30 A estos derechos, que son los que comúnmente se consagra, teleológicamente podríamos agregar otros, como el de inclusión en el banco de datos que podría ser reconocido, v.gr., cuando el Estado no tuviese incluidos en sus bancos de datos a determinados prestadores de servicios, como en el caso concreto de los listados de los hoteles que se hallan registrados en los servicios informatizados de la Secretaría de Turismo de la Nación, puestos a disposición de los turistas en los aeropuertos. En la normativa actual, tal vez podría considerárselo comprendido dentro del derecho de actualización. 
En cuanto a los aspectos procesales del Hábeas Data, cuando las constituciones se han ocupado de mencionarlos, (v. gr., Art. $43^{\circ}$ de la Constitución argentina), normalmente se ha recurrido a la figura del amparo, del cual, como dijimos, es un subtipo (Chubut y Corrientes), o bien se ha dejado la definición de tales aspectos a la ley reglamentaria (provincia de Buenos Aires).

En las provincias donde no está regulado, constitucionalmente, generalmente se lo puede introducir por vía de una cláusula abierta, como aquella que, por ejemplo, ordena amparar a todo derecho reconocido en las constituciones nacional o provinciales por vía de trámites breves (Corrientes, La Pampa y Santa Cruz).

Sobre este último aspecto, y desde un ángulo ideal, se observa que sería aconsejable realizar algunos pequeños ajustes respecto del amparo tradicional, adaptándolos a las necesidades propias del Hábeas Data, que tal vez lo acerquen en alguna medida al Hábeas Corpus (v. gr., declarando que la acción no estará sujeta a términos de caducidad; promoviendo la adopción de medidas cautelares de oficio; facultando al juez de la causa para que extienda los efectos de la sentencia a otras personas afectadas que no hubieran promovido la acción, etc. $)^{31}$.

\section{Conclusiones}

Como se habrá observado, tanto en la Argentina -en los niveles federal y local- como en el derecho latinoamericano, existen variantes de un instituto que en sí no es complicado, pero que muchas veces pareciera no haber sido captado en su esencia por el constituyente, tal vez por su reciente aparición en el mundo jurídico.

Por ello, las diferencias en las regulaciones muchas veces provocan confusiones conceptuales y llevan a amputaciones innecesarias del instituto, que debe ser regulado -constitucionalmente hablando- de una

31 En tal sentido, Santos Cifuentes indica que la del Hábeas Data "Es una norma procesal constitucional que rige y que debe ser aplicada en pro de la persona, de la misma manera que el amparo general allí establecido, valiéndose el juzgador de los elementos que, suficientemente evaluados y amoldados si es necesario, le permitan llegar al fin previsto de la tutela inmediata (Santos Cifuentes, "Protección inmediata de los datos privados de la persona. Hábeas Data operativo", L.L. 17/11/95, p. 1, nota al fallo de la C.N.Civ., Sala "H", 19/5/95, "Roserti c. Dun y Bradstreet, S.R.L."). 
manera simple y abierta, de forma tal que permita la adecuación a las más variadas posibilidades.

Es que, como indica Vanossi "el secreto del Hábeas Data está, precisamente, en su sencillez. Si al Hábeas Data se lo convierte en un mecanismo complejo demasiado sofisticado y demasiado articulado, no va a ser captado y entendido por los propios interesados, es decir, por los ciudadanos o por los habitantes que van a encontrar dificultades en el acceso al mismo para poderlo esgrimir y utilizar como herramienta protectora. Tiene que ser algo muy simple, muy sencillo, muy informal (quizás ésta sea la palabra que más cuadra a la descripción de la situación), para que cualquiera que se pueda sentir afectado por informaciones monopólicas que lo afectan o lo perjudican en su status, pueda entonces remover ese obstáculo tendiendo fundamentalmente a dos cosas: el derecho a la rectificación, a la anulación de aquellos asientos que puedan ser lesivos o perjudiciales" 32 .

Las regulaciones registradas en las provincias argentinas han tenido la virtud de servir como gran laboratorio, y sus escasas experiencias como preludio para su incorporación constitucional en la reforma de 1994, norma que fue, a su vez, evidentemente mejorada por las Cartas locales posteriores, en especial por el Estatuto-Constitución de la Ciudad de Buenos Aires.

Obvio es que resta mucho por hacer, pero todas las experiencias apuntadas han servido y sirven para que las futuras regulaciones constitucionales y subconstitucionales que se hagan del instituto se nutran de ellas y permitan la formulación de normas que sean respetuosas y promotoras de los avances tecnológicos, pero a su vez realmente garantistas de los derechos humanos.

32 Jorge R. Vanossi, "El Hábeas Data no puede ni debe contraponerse a la libertad de los medios de prensa”, E.D. 159-948. 